\title{
Using Multimedia to Promote Teaching Effectiveness in the Classroom of China
}

\author{
Jing Li \\ Office of Academic Affairs, \\ Luzhou Medical College \\ Luzhou, China \\ 740151140@qq.com
}

\author{
Muyun Kang* \\ Institute of Higher Education \\ Luzhou Medical College \\ Luzhou, China \\ 630173855@qq.com \\ *Corresponding author
}

\begin{abstract}
With the rapid development of information technology and the urgent need for modernization of pedagogy, multimedia-centered teaching techniques have come into use for classroom instruction. The application of multimedia devices to classroom teaching helps enlarge the amount of classroom information, enrich teaching content, enhance interactivity between teacher and student, increase teachers' personal competence and capacity for information, and as a result helps teachers achieve the goal of remarkably promoting teaching effectiveness in the classroom.
\end{abstract}

Keywords-multimedia;classroom teaching; teaching effectiveness

\section{INTRODUCTION}

Multimedia technology has drawn world-wide attention, and it has a wide range of application in many fields, exerting a strong influence on people's learning pattern, work and life style. The term multimedia was coined by singer and artist Bob Goldstein (later 'Bobb Goldsteinn') to promote the July 1966 opening of his "LightWorks at L'Oursin" show at Southampton, Long Island. Goldstein was perhaps aware of a British artist named Dick Higgins, who had two years previously discussed a new approach to artmaking he called "intermedia"(Zuras, 2010). The application of multimedia devices to classroom teaching helps enlarge the amount of classroom information, enrich teaching content, and enhance interactivity. Achieving the goal of remarkably promoting teaching effectiveness in the classroom plays significant role of multimedia in education.

\section{THEORETICAL PART: CONSTRUCTIVISM}

As perspective in education, Constructivism is based on experimental learning through real life experience to construct and conditionalize knowledge. It is problem based, adaptive learning, that challenges faulty schema, integrates new knowledge with existing knowledge, and allows for creation of original work or innovative procedures.

The types of learners are self-directed, creative, innovative, drawing upon visual/spatial, musical/rhythmic, bodily kinesthetic, verbal/linguistic, logical/mathematical, interpersonal, intrapersonal, and naturalistic intelligences. The purpose in education is to become creative and innovative through analysis, conceptualizations, and synthesis of prior experience to create new knowledge. The educator's role is to mentor the learner during heuristic problem solving of ill-defined problems by enabling quested learning. In this case, multimedia is selected in the study.

\section{DENOTATION OF ClASSROOM INSTRUCTION EFFECTIVENESS}

Classroom instruction is an important component of school education. Western scholars have summarized interpretations of pedagogic effectiveness, which could be roughly examined by looking at whether the expected pedagogical outcomes have been produced, into three basic categories: aim-oriented, skill-oriented, and achievementoriented. Although there is no consensus among western researchers on its definition, they agree on generalizing about it as pedagogy that helps students advance in their learning and development (Chen \& Stephen, 2005). Their Chinese counterparts tend to define it from different perspectives. Some interpret it from the students' point of view as effective, beneficial and efficient teaching pedagogics that successfully stimulates, sustains and increases students' interest in learning by its conformity to education laws, and consequently helps the teacher relatively efficiently attain pedagogical goals (Yao, 2004). Some others consider it in terms of interactive relations between students and teachers, defining it as practices that promote the mutual development between students and teachers through students' development-based and knowledge-impartingcentered tasks performed by both students and teachers in such effective manners as teaching after learning, learning after teaching, and synchronizing learning and teaching (Pan, 2011). Pedagogy consists of two-way interaction between teachers teaching and students learning, so this article is to follow the latter line of research to define effective teaching as endeavors to promote development both for students and teachers through classroom instruction activities.

\section{UtiLizing Multimedia TECHNOLOGY TO ENHANCE CLASSROOM INSTRUCTION EFFECTIVENESS}

Chinese government's Outline of China's National Plan for Medium and Long-term Education Reform and Development (2010-2020) mentions that information 
technology has revolutionary effects on education development, and therefore it is imperative to speed up the informationization progress of education, deepen the application of information technology, elevate teachers' level of applying information technology, renovate teaching ideas, improve teaching methods, and enhance teaching effectiveness. With the development of computer technology and the increasing popularity of computer, modern information technology with multimedia technology at its core has currently been more and more often utilized in the field of education and penetrated into course teaching in the classroom. Multimedia teaching refers to learning activities under best conditions that are made available by suitable teaching structure provided by carefully selected modern educational media and traditional teaching methods organically combined together, in accordance with instruction design based on pedagogical goals and characteristics of objects of teaching, throughout the teaching process during which multimedia elements act upon the students. Multimedia teaching contributes to the teaching reform of school education and to accelerating the pace of modernization process of education, and in the meantime it has shown itself to be of crucial importance for enhancing classroom instruction effectiveness.

\section{A. Enlarging the amount of classroom information to enhance classroom instruction effectiveness}

Multimedia systems translate differing media data into standard structure code streams, allowing such data management operations as exchange, recombination, analytical processing, storage, transmission, data output and interaction control (Lin, 2006). Multimedia technology has the characteristic of integrativity which refers to the processing and integration of various simplex information fragments enabling teachers to display to their students at the same time different kinds of media like text, image, and audio. It also provides for time control of display of most media in conformity with instruction design, and in so doing, reduces redundant and repeated pieces of course contents, and saves time meant for writing on the blackboard. Besides, multimedia technology is characteristic of being real-time. As the user input the operation commands, corresponding multimedia information is controlled in real time and displayed in precisely the same space and time. Thereby the amount of information students get per unit time is tremendously aggrandized. Within the same amount of time that traditional teaching methods would need, multimedia teaching can in a second get all resources pertaining to course displayed before the students. This makes a convenient, easily-accessed, and efficient way of teaching, which impalpably expands the amount of knowledge imparted in the classroom. It requires less teaching time than traditional teaching methods to help students accomplish stated learning tasks. In this way multimedia teaching offers alternate forms of pedagogy and innovation that speed up teaching process of classroom instruction, step up teaching efficacy, and consequently promote the effectiveness of classroom instruction.

\section{B. Enriching classroom teaching content to enhance classroom instruction effectiveness}

Multimedia technology allows teachers to integrate course content into multi-sensory representation via various digital media types and get students' sense organs stimulated, drawing their attention to audio and video synchronically. When stimulated in senses, students tend to be galvanized to learn course material with great interest. It is affirmed by scientific experiments that the senses of sight and hearing are the main receivers of human body for information, with the former accounting for 80 percent, and the latter, 10 percent, of the information received. Information conveyed via audio and video is easily absorbed and retained by students. Multimedia technology with its multisensory resource provides students with various types of learning material that enhance engagement and retention of course content, so as to elevate teaching efficiency and classroom instruction effectiveness.

\section{Boosting interactivity between teachers and students to enhance classroom instruction effectiveness}

In conventional education context, Chinese classroom instruction is a lecture-based process of information sending and receiving, which is a one-way directed instruction model with learners passively crammed in the learning process. By adopting multimedia teaching approaches, the traditional teacher-to-student interaction model involving only human is modified into an innovative interaction model of teachermedia-student involving both human and computer, which through the delivery medium of multimedia make both teachers and learners play great part in the learning process. Interactivity, as the major feature of multimedia technology that differs itself from traditional one-dimensional medium, enables both parts to assume an important role in creating, editing, controlling, and delivering information. Instructors present messages in multiple forms through multimedia technology and learners selectively absorb those that suit their needs based on their previous learning experiences. Thereby learners are more likely to learn on their own initiative. Constructivists contend that since all learners accumulate their experiential knowledge in life and learning experiences, they should find in various available resources new areas for experiential knowledge growth through constructivist perspective. "Educators' chief obligation is no longer to deliver the lecture content but to stimulate and retain learners' interest in learning, create teaching situations suitable to the course content, address to the linking connection between new and old pedagogical messages, and help learners constructively comprehend the knowledge obtained." Therefore, employing the interactivity feature of multimedia technology in teaching creates a constructive environment for learners, provides tremendous support for instructors to present miscellaneous media information and for learners to construct experiential knowledge framework, and enhances two-way interaction between teachers and students, thereby resulting in higher levels of classroom instruction quality and effectiveness. 


\section{Elevating teachers' personal competence and capacity for information to enhance classroom instruction effectiveness}

The teacher plays the predominant role in conventional teaching practices concentrating on textbooks and lecture notes, with verbal aptitude and blackboard presentation being important measurement standards for evaluating teaching competence. With multimedia-orientated computers entering the classroom, students no longer face insipid blackboard. Instead, they now have imaginary screens potential of all possibilities displayed before them. This makes it a vital means to attract students' attention that teachers work out appealing, vivid and exquisite multimedia courseware. These days, PowerPoint, due to its user-friendliness, is basically the most popular application software in use in the classrooms of China's higher education institutions. It allows for digital multimedia such as text, images, audio, as well as animation effects to be inserted into slides. However, it suffices only for general courses instruction. For those more obscure and abstract majors that require greater specialization, it is necessary to utilize courseware application software of higher level of complexity and delicacy in order to more vividly show the course-pertaining content. For example, into medical science are subsumed many courses that contain abstract content hard to be described and delivered. In the pre-technology education context, teachers used to adopt plane wall maps and models to lecture medical science courses. With advanced application software of animation design, which integrate multiple types of digital media (like text, diagrams, images, audio, video and animation effects) into one, they now can impress the students with more directly perceived information and thereby improve their understanding about the course content. It calls for teachers' higher proficiency in making multimedia courseware. In this way, multimedia technology on entering classrooms promotes teachers' adeptness at employing computers and mastering modern pedagogical skills, which not only acclimates themselves to the needs of development of the information society as well as their own career, but also elevates their personal competence and capacity for information, thereby resulting in higher levels of classroom instruction quality and effectiveness.

\section{CONCLUSION}

It is an inevitable trend of information society development and education modernization for multimedia technology to enter classrooms. The application of multimedia technology into classroom instruction innovates on outdated teaching methods and techniques confined within the conventional one-way directed pedagogical model of "teacher cramming + student passively spoon-fed" instruction. It promotes interactivity between instructors and learners, encouraging and enhancing students' engagement in the learning process. The major features of integrativity, interactivity, and being real-time provide encouraging environments for students to learn with greater interest, initiative and creativity, and thereby remarkably improve classroom instruction effectiveness as well as the mutual development of teachers and students.

\section{REFERENCES}

[1] ZURAS, M.. Teach art history. Part 2. June 2010, Retrieved from http://www.switched.com/2010/ 06/03/tech-art-history-part-2/

[2] Chen Xiaorui and Stephen Keith, "Research on Effective Teaching in Modern Western Countries:Systematical Review and Some Inspirations," COMPARATIVE EDUCATION REVIEW, vol. 26, Aug. 2005, pp. 56-60.

[3] Yao Limin, "Characteristics of effective teaching," FORUM ON CONTEMPORARY EDUCATION, Nov.2004, pp. 23-26.

[4] Pan Chao. "Reconstruction of the concept of effective teaching," JOURNAL OF TEACHING AND MANAGEMENT, Mar.2011, pp.6-7.

[5] Lin Zhong and Feng Ruiqin. "Cognitive mechanisms in multimedia teaching,” EDUCATIONAL RESEARCH, July 2006, pp.62-66. 